\title{
A Novel RFID-Based Outdoor Billboard Management System
}

\author{
Hui Jiang, Jianjun Yi*, Shaoli Chen, Xiaomin Zhu and Zhuoran Wang \\ Department of Mechanical Engineering, East China University of Science and Technology, 130 Meilong Rd, Shanghai, China \\ ${ }^{*}$ Corresponding author
}

\begin{abstract}
A billboard is a large board that shows advertisements. In China, billboard management relates to several government departments. The inspection staff must records status of specific billboards and compares the status with register information manually. This paper proposes a novel RFID-based billboard management system. At first, the paper analyzes the system framework and its application. The authors analyze requirements, design entity-relations of database, and implement the proposed system. The demonstration shows that the system makes billboard management efficiently.
\end{abstract}

Keywords- billboard; RFID; management system

\section{INTRODUCTION}

Billboards are usually installed in shopping centers or along the highway, which display various advertisements. Big cities face some problems of managing billboards, including (1) some advertisers install billboard without approval; (2) a lot of billboards exceed their permitted lifetime and they are still not dismantled; (3) the contents of some billboards against rules; (4) there exists billboards that being constructed over permitted size, which is a threat to the city safety. Therefore, it is very important to manage the billboards efficiently.

In order to manage the billboards, at present, inspection staffs records the key information and location of billboards, then, they compares the status of billboards to register information of specific billboard. Nevertheless, some areas have high densities of billboards, the amount of billboards increases greatly in big cities, and it is also inefficient for staffs to compare the data. As a result, more and more government departments pay attention to improve the management level of the billboard inspection.

To solve the problems mentioned above, this study proposes a novel RFID-based billboard management system. In this system, each billboard embodies a RFID tag which shall be installed along with the billboard. Inspection staffs have portable readers to read information from RFID tags. Thus, the inspection staffs are able to acquire identity (ID) numbers of the billboards through the readers. Then, inspection staffs are capable of comparing the status of the billboards and the register information with the ID numbers. They can decide whether the billboards are legal or not. This method significantly improves the efficiency of billboard management.

\section{LITERATURE REVIEW}

RFID technology is regarded as one of ten greatest inventions in the 21st century [1]. It is an emerging technology that is able to identify objects without physical touch. RFID recognizes target object and acquires ID numbers automatically through radio frequency signal. RFID system consists of reader and tag, the reader writes ID number to the tag and acquires the number of the tag wirelessly. Hardware of a traditional reader includes RF chip, micro control unit and antenna. In recent years, RFID technology has been widely used in many areas such as food industry [2, 3], public health [4-6], and inventory management [7].

As discussed above, RFID technique has been widely applied, but there doesn't have many studies relating to the RFID-based billboard management system. Total Computer Software (India) Pvt. Ltd. developed a billboard management system. In this system, tags are installed inside billboards, inspection staffs acquire the information of billboard with mobile devices. However, the system has two disadvantages:

- There is no GIS function in current mobile devices. That is, billboard tracking, locating and some related functions based on GIS have not been implemented in RFID-based billboard management system.

- Various departments cannot share billboard information. In China, billboard management relates to several departments such as Department of Municipal Administration, Department of Industry \& Commerce and Department of Urban Management. So, an integrated platform is required for sharing billboard information.

\section{FRAMEWORK AND APPLICATION OF RFID-BASED BILLBOARD MANAGEMENT SYSTEM}

\section{A. Framework of Billboard Management System}

As shown in FIGURE I, the system proposed in this paper includes: (1) billboard information service center; (2) billboard register department; (3) on-site inspection; (4) billboard management departments. The details are discussed following.

- Billboard information service center contains information server and application server. A relational database system is installed and running on the information server, which is used to store billboard information. The application server provides web service, thus users can acquire and manage the information through internet. 
- Billboard register department mainly employs computers and readers. Each tag has a unique ID number for identifying purpose. When registering a billboard, user can get the ID with the reader. After that, the ID number and relevant billboard information shall be added to the database. Finally, the tag should be installed on the corresponding billboard.

- Inspection staffs are responsible for check billboards periodically. They take portable readers, and walk or in a car. After reading tags, the portable readers can get detailed data from billboard information center through wireless network. Then, they compare billboard information and on-site situation to determinate whether the billboard is violation or not. If a billboard happens against rules, the portable reader will send its violation records to the billboard information center. The billboard management department takes further action on illegal billboards.

- Billboard management department is in charge of inserting new billboard data, examining, and verifying and maintaining billboard information. This department is also response for receiving and analyzing the on-site inspection information. Staffs of the department should decide measures to handle illegal billboards.

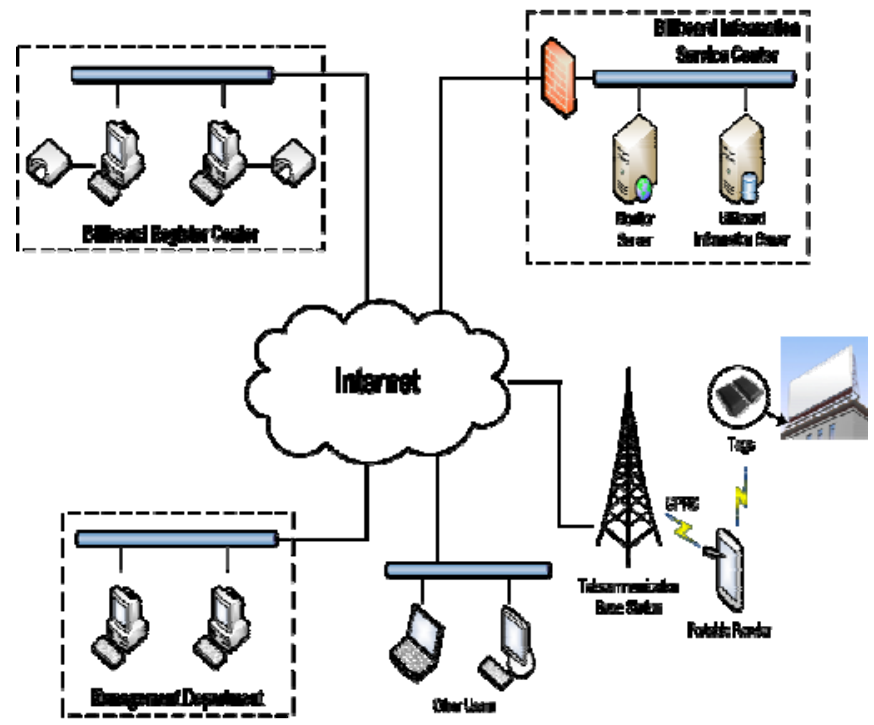

FIGURE I. FRAMEWORK OF BILLBOARD MANAGEMENT SYSTEM

The system proposed in this paper provides services by an information center, all operation terminals are possible to communicate through the internet. Thus different departments can share the billboard information and access the information from other departments.

\section{B. Application of Billboard Management System}

Inspection staffs take portable readers and check billboards either on foot or in a car, flowchart of inspecting billboards is shown in FIGURE II. First of all, the inspection staff uses a portable reader to get IDs of nearby billboards. Then the reader connects billboard information server through wireless network and gets brief billboard information according the IDs. The brief information contains billboard position which is used in GIS, the inspection staff can find the target billboard quickly. After that, more information of the billboard will be obtained from the server according to its ID. The inspection staff compares the billboard information to current billboard status, and makes a decision that whether the billboard is legal or not. If it is against rules, the inspection staff shall record and send illegal information to the server, the information will be stored in the database. Other departments deals with illegal ones after inspecting billboards. The staff can check other billboards if the billboard is well.

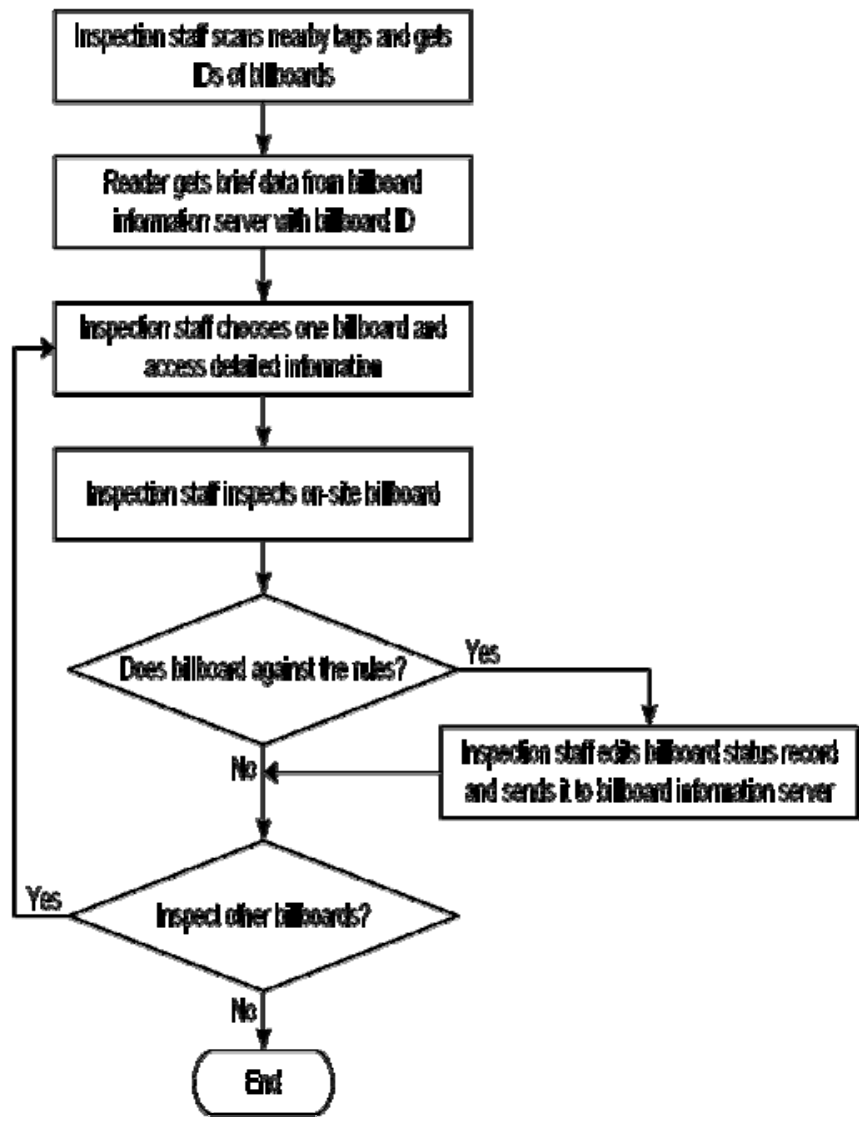

FIGURE II. FLOWCHART OF INSPECTING BILLBOARD WITH PROPOSED SYSTEM

\section{IMPLEMENTATION OF RFID-BASED BILLBOARD MANAGEMENT SYSTEM}

Rules for publishing and managing billboards are various from countries, it is necessary to design a software meeting specific requirements of users. This paper designs the software according to billboard examining, approval and management rules in China, FIGURE III shows the use case diagram. There are four roles in this software, Municipal Staff, Inspection Staff, Industry \& Commerce Staff and System Administrator. In each department related to billboard, staffs of that department are allowed to access corresponding software modules. But all departments share the billboard information module to achieve the purpose of sharing billboard information. 


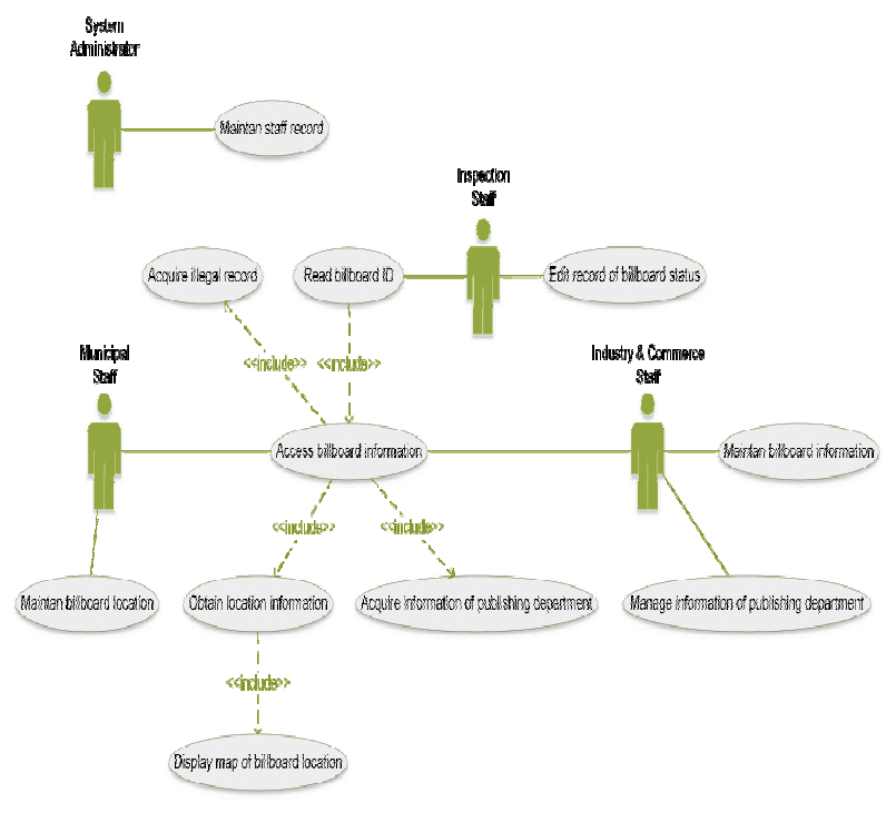

FIGURE III. FIGURE III. USE CASE DIAGRAM OF THE MANAGEMENT SOFTWARE

\section{A. Database Design of Billboard Management Software}

To make various departments sharing billboard information, we analyze the requirements of RFID-based billboard management system and establish a software E-R model, as shown in FIGURE IV. This model defines five entities, there are billboard, site, inspection record, department and system user. Following content discusses the entities in detail.

- Billboard entity, including type, content, etc., represents the basic information of billboard.

- Site entity, including region, road, etc., represents installing information of billboard.

- Inspection record, including date, detail, etc., represents inspection result of billboard.

- Department entity, including name, contacts, etc., represents the information of billboard publisher.

- System user entity, including name, password, is used for user verification and user authority management.

Each entity has relations with other entities, the relations are also shown in FIGURE IV. The relations include: (1) One Site installs different billboards in different time; (2) One billboard has one or several inspection records; (3) Different system users are able to manage the same billboard; (4) One inspection staff saves one or several inspection records; (5) One department delivers one or several billboards.

The database of RFID-based billboard management software is built according to the E-R model established above, it will be configured and running in billboard information service center as shown in FIGURE I. Users are able to acquire data with the software through the internet. Staffs from different departments take charge of maintaining different parts of data in database.

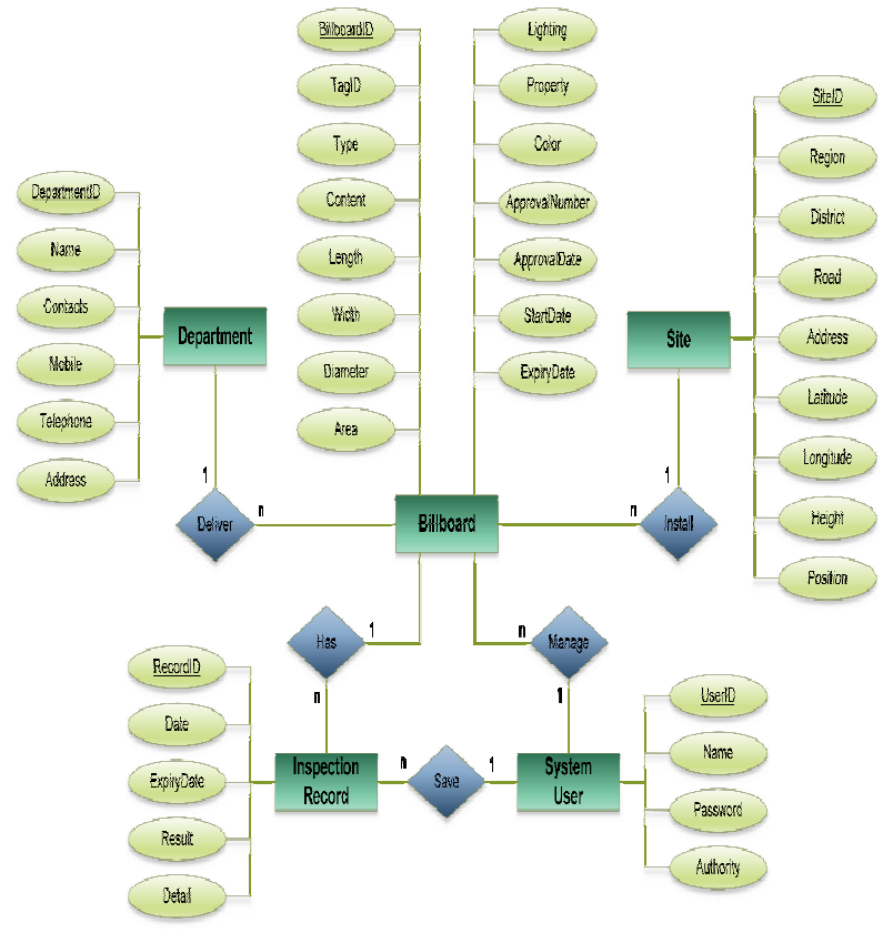

FIGURE IV. DATABASE E-R DIAGRAM OF BILLBOARD MANAGEMENT SOFTWARE

\section{B. Implementation of Billboard Management Software}

This part implements the required functions of the software on the basis of the use case and database of the billboard management software. This study develops user interface for improving the user experience of the software. For developing user interface, there are many integrated development environments such as Visual Studio, Delphi and Eclipse. In this paper, we use Netbeans which enjoys higher versatility. Netbeans is also convenient for the development of user interface of the billboard management software. It is a javabased platform, java programs are able to run in Windows, Linux and other operating systems. To demonstrate the application of the system, we use tablet computer as mobile device. Tablet computers, like iPad and Surface, are popular over the years, they are easy to carry and have excellent user experience. Surface runs Windows 8 operation system, so java programs are able to run on it. So, the billboard management software runs on tablet computer, the reader module and the tablet computer exchange data and instructions through UART or USB port. As a result, the inspection device are simple and the hardware cost is cheap.

The software consists of seven sub systems, sub system are introduced in following content.

a) Sub system for querying billboard information: This sub system is responsible for querying and displaying billboard information. Basic information of billboard includes location and publisher of the billboard. Users can get more 
information related to the billboard such as inspection record besides the basic information. Billboard region and business district are two key words for searching billboard information. Particularly, if the user is an inspection staff, the billboard location will be signed on the map after searching.

b) Sub system for billboard position management: It is necessary to plan and manage installing positions of billboards, because the positions install different billboards in different time. This sub system focuses on adding, searching, deleting and revising installing positions of billboards.

c) Sub system for managing information of billboard publisher: This part is responsible for managing information of billboard publisher. One publisher may deliver several billboards, so this sub system is specialized for publisher information adding, searching, deleting and revising operations.

d) Sub system for billboard information management: This sub system is used for acquiring information such as billboard location, publisher and other related information, so it is a comprehensive management sub system. Main functions include creating new billboard, deleting billboard and revising billboard data.

e) Sub system for reading tags of billboards: This one is designed for inspection staffs, it can get the billboard ID numbers from reader module and list them in a table. Then the inspection staff chooses one to acquire further information of the billboard.

f) Sub system for recording inspection information of billboard: This sub system is responsible for recording billboards inspection results, it will generate violated information if the billboard is against the rules. After that, the information will be stored in the database.

g) Sub system for software administrator management: To ensure the security of the software, this sub system manages users. There are several different user roles, normal users are only permitted to access billboard related information. The software administrator, on the other hand, is responsible for creating, deleting and revising user accounts.

\section{SYSTEM DEMONSTRATION}

A tablet computer is adopted in this demonstration, the CPU of it is Intel Atom N2600. Other hardware parameters are 2GB RAM, 64GB SSD and 9.7' touch screen.

Billboard information is a module shared by various departments, the user interface is shown in FIGURE V. Users can query billboard information by selecting region and business district of billboards, all the billboards in selected area will be listed on the interface. If the user wants to know more about a specific billboard, he or she can click one, then the software will show all the information about it. Some users are also able to create, revise and delete billboard data. The other software modules involving operations create, read, update and delete are similar to this module.

The inspection staff gets the ID numbers of billboards from tags, the results show in billboard inspection module, which is shown in FIGURE VI. Users are able to access information such as billboard ID, battery voltage and signal strength. Rough positions information of billboards are listed in the interface by querying database with billboard ID numbers. This makes inspection staffs easier to find relevant billboards. When the staff clicks a specific billboard in the list, the software will show the detail information of the billboard and mark it on the map. If the staff finds that the billboard is illegal, the staff can record the inspection results of the billboard.

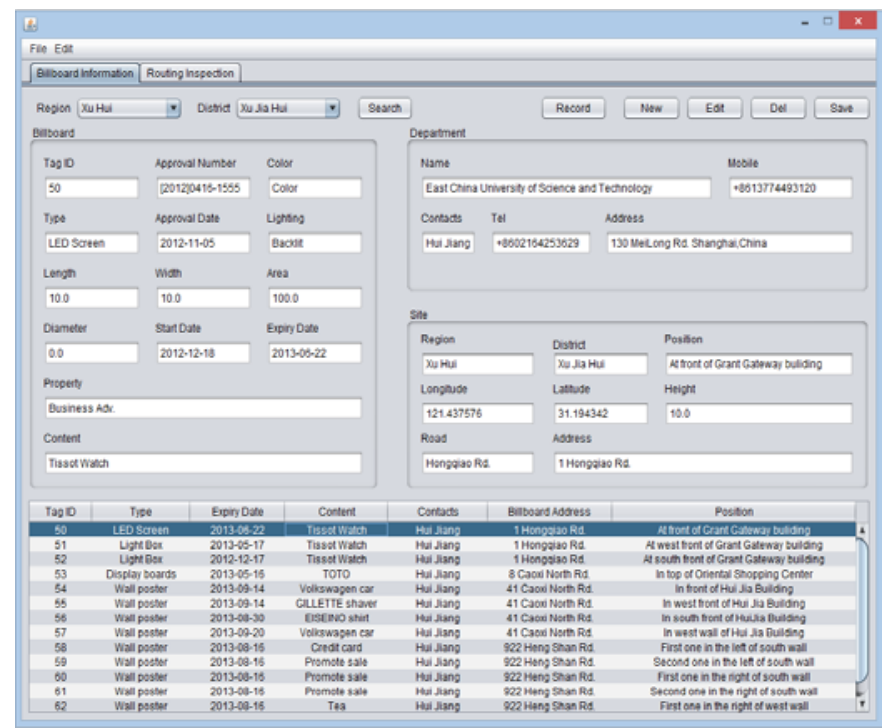

FIGURE V. SCREENSHOT OF BILLBOARD INFORMATION MODULE

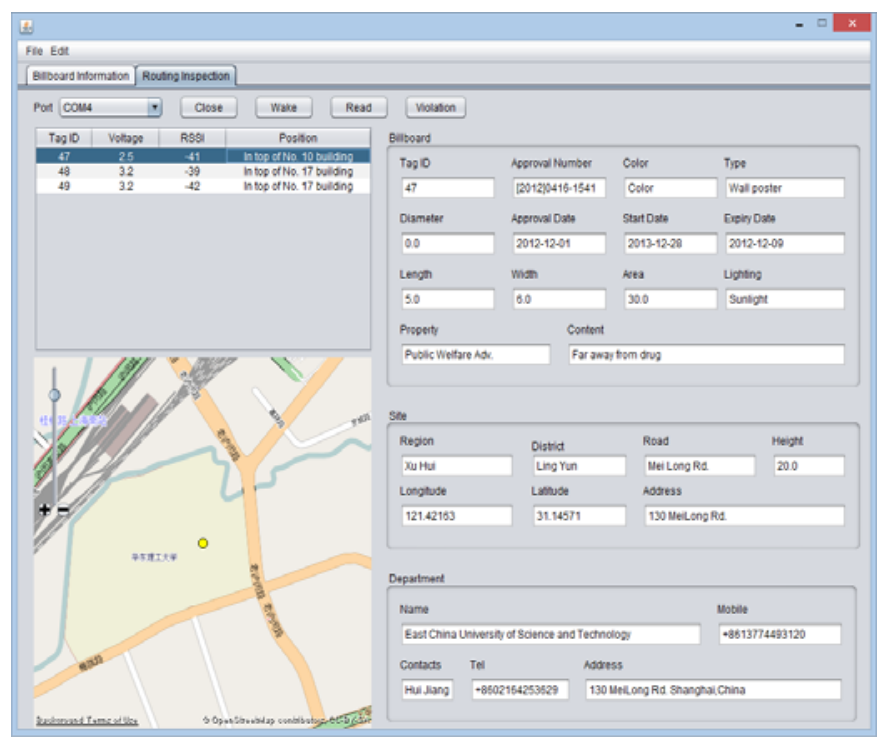

FIGURE VI. SCREENSHOT OF BILLBOARD INSPECTION MODULE

\section{CONCLUSION}

This paper proposes a RFID-based billboard management system which combines RFID technology and billboard management. The RFID tags are installed on billboards, this makes the billboard have a unique ID number. After 
inspection staff gets billboard ID number with portable reader, detailed information of the billboard can be obtained and be shown the information on the software interface. The system also has a billboard GIS sub system, the sub system marks the billboard position on map. Besides, in order to share the billboard information, a unified management system for billboard information was established. The proposed system can also be applied in areas such as container management, car management and dangerous cargo.

\section{ACKNOWLEDGMENT}

This paper is funded by the Nature Science Fund of China (NSFC) under Grant Nos,50975088, 51275173, 51210105018, the Fundamental Research Funds for the Central Universities under Grant No.WH0913009, the Shanghai Pujiang Program under Grant No. PJ201000353. Any opinions, findings, and conclusions or recommendations presented in this paper are those of the authors and do not necessarily reflect the views of the above foundation.

\section{REFERENCES}

[1] T. H. Tan and C. S. Chang, "Development and evaluation of an RFIDbased e-restaurant system for customer-centric service,” Expert Syst. Appl., vol. 37, no. 9, pp. 6482-6492, 2010.

[2] L. Mainetti, F. Mele, L. Patrono, F. Simone, M. L. Stefanizzi, and R. Vergallo, "An RFID-Based Tracing and Tracking System for the Fresh Vegetables Supply Chain,” Int. J. Antennas Propag., vol. 2013, 2013.

[3] K. H. Eom, M. C. Kim, and S. Lee, "The vegetable freshness monitoring system using RFID with oxygen and carbon dioxide sensor,” Int. J. Distrib. Sens. Netw., vol, 2012, 2012.

[4] V. Chawla and D. S. Ha, “An overview of passive RFID," IEEE Commun. Mag., vol. 45, no. 9, pp. 11-17, 2007.

[5] S. Y. Ye and H. K. Jo, "The Display System of a Patient's History Using the RFID and Linux,” Int. J. Distrib. Sens. Netw., vol, 2013, 2013.

[6] H. Alemdar, Y. Durmus, and C. Ersoy, "Wireless healthcare monitoring with RFID-enhanced video sensor networks,” Int. J. Distrib. Sens. Netw., vol. 2010, 2010.

[7] Y. Y. Chen, J. K. Jan, M. L. Tsai, and C. C. Ku, "On The Security of RFID-based Monitoring Mechanism for Retail Inventory Management," KSII Trans. Internet Inf. Syst., vol. 6, no. 2, pp. 515-528, 2012. 